\title{
REPRESENTAÇÕES E RELAÇÕES DE GÊNERO NOS GRUPOS PENTECOSTAIS
}

\author{
MARIA DAS DORES CAMPOS MACHADO \\ Universidade Federal do Rio de Janeiro
}

\begin{abstract}
Resumo: O objetivo deste artigo é realizar um balanço das principais transformações ocorridas nos últimos 15 anos no sistema de gênero hegemônico no pentecostalismo. Inicialmente, procuro apresentar o perfil demográfico e socioeconômico dos pentecostais. Em seguida, discuto as conseqüências da opção religiosa dos homens e das mulheres e chamo atenção para os limites do processo de reconfiguração das subjetividades femininas e masculinas no interior das comunidades. O exame das tendências de crescimento do sacerdócio feminino e da participação política das mulheres pentecostais complementa esta análise e ajuda no entendimento das ambivalências na revisão das representações e relações de gênero nesses grupos religiosos.
\end{abstract}

Palavras-chave: relações de gênero, pentecostalismo, política.

As duas últimas décadas do século $X X$ foram marcadas por importantes transformações quantitativas e qualitativas no campo religioso brasileiro. Em termos quantitativos, os recenseamentos demográficos realizados pelo Instituto Brasileiro de Geografia e Estatística (IBGE) revelam a aceleração da tendência de declínio dos católicos e a intensificação da expansão dos evangélicos e dos sem religião. Assim, enquanto a representação dos católicos na população brasileira caiu de $83,3 \%$ para $73,8 \%$, a porcentagem dos evangélicos pulou de 9,0\% para 15,4\% entre 1991 e 2000'. Já os sem religião subiram de $4,8 \%$ para $7,3 \%$ nesse mesmo período. Tendo em vista os propósitos deste artigo, deter-me-ei no extraordinário crescimento dos evangélicos e no perfil demográfico e socioeconômico dos grupos em expansão.

De início, é bom informar que a curva ascendente dessa categoria religiosa está diretamente relacionada com a difusão e a diversificação do pentecostalismo. Afinal, representando $49 \%$ dos evangélicos identificados em 1980, os pentecostais deixaram para trás os chamados protestantes históricos nas duas décadas seguintes, com sua taxa subindo para $67 \%$ em 1991 e $68 \%$ em 2000. Além disso, é preciso lembrar que os evangélicos encontram-se entre os grupos religiosos que apresentam as maiores taxas de fiéis do sexo feminino em suas fileiras. Para ser mais precisa, a proporção das mulheres -

Copyright (c) 2005 by Revista Estudos Feministas

I Ver Rosa Amélia de Almeida WEISS, 2002; César Romero JACOB, 2003; e Antônio Flávio PIERUCCI, 2004. 
$56 \%$ - é superior em 5 pontos percentuais à representação feminina na população brasileira - 51\% -, e só perde para os espíritas, onde as mulheres representam $59,7 \%$ dos recenseados. Deve-se lembrar ainda que, em várias denominações pentecostais - Igreja Universal do Reino de Deus, Evangelho Quadrangular, Deus é Amor, etc. -, a desproporção entre os homens e as mulheres mostra-se maior do que aquela encontrada no conjunto dos evangélicos, o que acaba por dar um rosto feminino ao pentecostalismo. É importante registrar também que, em matéria de educação e de renda, os pentecostais se caracterizam por baixos níveis de instrução e de remuneração, uma vez que possuem sobretudo o curso de alfabetização de adultos, o antigo primário e o primeiro grau, e recebem até três salários mínimos².

Em termos qualitativos, observa-se a crescente dificuldade das instituições tradicionais em regular e manter seus adeptos dentro dos limites seguros e estáveis de seus sistemas de crença, produzindo, conseqüentemente, a intensificação do trânsito religioso e da competição entre as estruturas eclesiásticas. ${ }^{3}$ No segmento pentecostal, tais tendências teriam resultado em uma flexibilização da moral e dos costumes e em uma incessante revisão das estratégias de recrutamento dos fiéis e das formas de atuação das lideranças religiosas, tanto no interior da denominação quanto na sua representação na sociedade mais ampla.

Demonstrando uma invejável capacidade de selecionar, ressignificar e incorporar elementos de outras tradições confessionais e da cultura política dos movimentos sociais, o pentecostalismo adquiriu uma plasticidade e um caráter dinâmico que parecem paradoxais ao tradicionalismo que marcou a maior parte da história desse ramo do evangelismo. Basta lembrar que entre as principais características identificadas pelos estudiosos desses grupos até meados dos anos 1980 estavam: a rigidez moral, o apoliticismo, a opressão feminina e o apartamento da cultura brasileira, expresso, entre outras coisas, na severa condenação ao futebol e ao carnaval. ${ }^{4}$ Neste artigo, pretendo realizar um balanço das principais mudanças identificadas nos últimos 15 anos nas representações e relações de gênero dos pentecostais e quais são os limites do processo de revisão dos arranjos de poder entre os homens e as mulheres que integram esse segmento religioso.

\section{Escolhas religiosas e a reconfiguração das subjetividades masculinas e femininas}

A tendência de interiorização ou subjetivização das escolhas religiosas está estreitamente relacionada ao longo processo de individuação dos atores sociais nas sociedades modernas e pós-modernas. Na literatura socioantropológica brasileira existe o consenso de que a expansão do pentecostalismo é uma expressão dessa tendência nas camadas populares. Afinal, a decisão de tornar-se pentecostal em uma sociedade majoritariamente católica exprime não só uma opção consciente e deliberada do indivíduo, mas também uma tensão entre este e o mundo social mais amplo. Dito de outra maneira, a adesão ao pentecostalismo representa uma ruptura com as expectativas sociais e simultaneamente um corte na própria biografia do indivíduo. A perspectiva de gênero me leva a acrescentar que a opção de ingressar nesse movimento religioso resulta de experiências bastante diferenciadas dos homens e das mulheres e pode produzir modificações nas relações de gênero.

\footnotetext{
2 JACOB, 2003, p. 40.

${ }^{3}$ Maria das Dores Campos MACHADO e Cecília Loreto MARIZ, 1999.

${ }^{4}$ Ver MACHADO, 1996, p. 153.
} 
As histórias de conversão masculinas revelam situações de desemprego, dificuldades financeiras e problemas pessoais na área da saúde nas justificativas para a adesão religiosa ao pentecostalismo; já as mulheres quase sempre associam suas escolhas religiosas com as desavenças familiares e as necessidades - materiais e espirituais - do grupo doméstico. Em outras palavras, enquanto os homens procuram a comunidade religiosa em situações que põem em ameaça a identidade masculina predominante na sociedade, as mulheres se colocam como guardiãs das almas de todos que integram a família, buscando os grupos confessionais sempre que um dos seus familiares se mostre em dificuldades. Nesse sentido, as qualidades alocadas ao gênero masculino no sistema hegemônico de representações parecem distanciar os homens das prescrições religiosas de uma forma geral e, em especial, do ethos pentecostal, enquanto os atributos femininos favorecem as experiências das mulheres com o sagrado e os vínculos com as comunidades religiosas.

A doutrina pentecostal enfatiza os valores associados à subjetividade feminina, mas tal fato não deve ser interpretado como um simples reforço à submissão das mulheres, uma vez que esses princípios, bem como os constrangimentos à sexualidade, são extensivos aos homens da comunidade. Ou seja, o pentecostalismo combate a identidade masculina predominante na sociedade brasileira, estimulando nos homens que aderem ao movimento as formas de conduta e as qualidades tradicionalmente alocadas ao gênero feminino. Assim como as mulheres, estes devem ser dóceis, tolerantes, carinhosos, cuidadosos, etc., levando uma vida ascética regida por uma moral sexual rígida. Além disso, espera-se que os mesmos se preocupem com o bem-estar da família, dedicandose mais à educação e ao acompanhamento dos filhos. Tais expectativas revelam uma reconfiguração da subjetividade masculina, criando a possibilidade de arranjos familiares mais igualitários. Esses processos têm sido interpretados como tendências à "domesticação dos homens pentecostais" ou à "androginização" das famílias populares. ${ }^{5}$

A adesão a essa forma de religiosidade também provoca a redefinição da subjetividade feminina ${ }^{6}$ na medida em que o pentecostalismo estimula $\circ$ processo de autonomização das mulheres diante dos seus maridos e filhos. A conquista de uma autoridade moral e o fortalecimento da auto-estima ampliam as possibilidades de as mulheres desenvolverem atividades extradomésticas e as redes de sociabilidade, favorecendo, conseqüentemente, a individuação feminina. Sinteticamente, o engajamento nesses grupos possibilita às mulheres também uma maior participação na esfera pública, com algumas pentecostais evangelizando em praças públicas, realizando trabalhos voluntários em presídios, hospitais e entidades filantrópicas, participando de programas religiosos televisivos e radiofônicos ${ }^{7} \mathrm{e}$, mais recentemente, dedicando-se à militância política em favor dos candidatos da igreja.

Como exposto anteriormente, o estímulo à individuação não se circunscreve ao universo feminino, uma vez que os fiéis, independentemente da identidade sexual, aprendem "a ver a si mesmos como seres autônomos que são igualmente responsáveis por seu sucesso e destino". ${ }^{8}$ Entretanto, a existência de um hiato temporal nos processos de individuação de homens e mulheres das diferentes classes sociais indica que a opção das mulheres das camadas populares pelo pentecostalismo favorece a expansão da cultura individualista nos extratos sociais onde predomina a visão de mundo hierárquica e

${ }^{5}$ Ver Monica TARDUCCI, 1994; e MACHADO, 1996.

- MACHADO, 1996; Maria das Dores Campos MACHADO e Cecília Loreto MARIZ, 1996.

${ }^{7}$ MACHADO, 1999; e Eliane GOUVEIA, 1998.

${ }^{8}$ MACHADO e MARIZ, 1994. 
baseada na família. E aqui deve-se lembrar também que, com a incorporação da teologia da prosperidade no sistema axiológico dos principais grupos pentecostais, as lideranças passaram a estimular a entrada das fiéis no mercado de trabalho, o que certamente auxilia na criação de novas zonas de autonomia individual.

Pesquisas demonstram o crescimento acentuado da participação das mulheres pobres na população economicamente ativa durante os anos 1990. E esse é fenômeno novo, uma vez que nas décadas anteriores as taxas de representação desse segmento foram significativamente inferiores às das mulheres dos extratos médios e altos da sociedade brasileira. Entre os principais obstáculos enfrentados pelas mulheres pobres no mercado de trabalho, os estudiosos/as identificam: o baixo nível de escolaridade e qualificação, a ausência de apoio no cuidado das crianças e na realização das tarefas domésticas e "as barreiras culturais para sair em busca de um trabalho remunerado". ${ }^{9}$ A pertença a uma igreja que reforça a auto-estima, enfatiza o presente e estimula a busca da prosperidade certamente ajuda na superação dos constrangimentos da cultura tradicional, favorecendo a participação da mulher na esfera econômica.

Parece consensual que a produção de novas formas de subjetividade feminina e a reconstrução das identidades de gênero na sociedade brasileira desta virada de século estão estreitamente relacionadas com o incremento do nível educacional das mulheres, a ampliação da participação em atividades remuneradas, o aumento do número de separações e o crescimento da chefia feminina das famílias. Entretanto, são múltiplos os recursos discursivos e simbólicos acionados pelas mulheres nesse processo. Nos setores médios a cultura psicanalítica fornece elementos argumentativos para a revisão do conceito de indivíduo e liberdade individual; já a cultura feminista proporciona os recursos discursivos para o desenvolvimento de uma consciência de gênero e para o combate das relações assimétricas entre os homens e as mulheres. De forma diversa, percebe-se que as pentecostais das camadas populares têm identificado nos valores religiosos que também propugnam o individualismo os elementos que dão sentido à reestruturação das suas condutas, das relações familiares e das expectativas em relação à vida. ${ }^{10}$

Em outros artigos, estabeleci as distinções entre o individualismo pentecostal e o feminista, e alertei os leitores de que o fortalecimento da auto-estima das mulheres e o desenvolvimento de relações mais simétricas nas famílias onde os cônjuges partilham os valores pentecostais não devem ser interpretados a partir do ideário feminista. ${ }^{11}$ Aqui caberia acrescentar que, a despeito do combate das lideranças religiosas pentecostais ao movimento de mulheres, as mudanças nas representações dos gêneros nesses segmentos confessionais encontram-se também relacionadas com a tendência de apropriação seletiva de idéias feministas pela sociedade, e em especial pelas instituições culturais brasileiras. Mostrarei nas sessões seguintes que a competição religiosa e os projetos de ampliação da capacidade de influência favorecem a assimilação de alguns temas dos movimentos de mulheres e a adaptação das igrejas às mudanças em curso na sociedade.

\footnotetext{
${ }^{9}$ Vera SOARES, 2004, p. 174.

${ }^{10}$ MACHADO, 2003, p. 69

$"$ MACHADO E MARIZ, 1994 e 1996.
} 


\section{O sacerdócio feminino e a acomodação às tradicionais prescrições de gênero}

Estudos recentes sobre a distribuição de autoridade no interior das igrejas revelam a tendência de revisão dos constrangimentos à participação das mulheres na direção das comunidades pentecostais, destacando o crescimento do número de denominações com pastorado feminino e a multiplicação das igrejas fundadas por mulheres. ${ }^{12}$ Nesse sentido, cabe esclarecer que, embora a história do protestantismo indique a implementação do sacerdócio feminino no território brasileiro pela igreja pentecostal Evangelho Quadrangular em meados dos anos 1950, o impacto dessa iniciativa foi, entretanto, reduzido até os anos 90 do século passado, com pouquíssimas igrejas evangélicas adotando o pastorado feminino. Foi também nesta última década que surgiram novas estruturas eclesiásticas lideradas por mulheres. ${ }^{13}$

Ainda que fortemente associada à expansão neopentecostal, a tendência de revisão do sistema de autoridade não está circunscrita ao segmento mais novo da tradição evangélica. Movimentos em favor da consagração de mulheres já podem ser percebidos tanto na Assembléia de Deus, uma das mais tradicionalistas e sexistas denominações do pentecostalismo clássico, quanto na comunidade Batista, que é a maior e mais popular igreja do protestantismo histórico em nosso país. ${ }^{14}$ Além disso, é importante deixar claro que nem sempre as mudanças nas hierarquias eclesiásticas resultam das reivindicações e da pressão das mulheres que as integram. Fatores de outra natureza, como por exemplo o acirramento da competição religiosa e o reduzido número de homens para o sacerdócio podem favorecer a adoção do pastorado feminino em algumas igrejas. Assim, torna-se imprescindível o exame dos critérios e dos mecanismos mais comuns de ascensão das mulheres para se avaliar o impacto das propostas feministas de maior eqüidade entre os gêneros nas agremiações pentecostais.

Em se tratando de um fenômeno recente, a consagração de mulheres ao sacerdócio ainda necessita de uma pesquisa mais ampla e comparativa envolvendo as diversas denominações religiosas. Entretanto, as primeiras análises sobre o tema sugerem uma forte associação entre o sacerdócio feminino e o laço matrimonial, uma vez que a maioria das pastoras é casada com homens que ocupam cargos hierárquicos iguais ou superiores em suas denominações. ${ }^{15}$ As trajetórias de algumas das mais expressivas lideranças pentecostais revelam a importância dos vínculos domésticos e o papel decisivo dos homens no processo de ascensão das mulheres nas hierarquias religiosas. ${ }^{16}$ Restaria analisar os artifícios desenvolvidos pelos dirigentes do sexo masculino para garantir 0 controle sobre a atuação feminina no púlpito.

As mais importantes estratégias já identificadas nas igrejas que abandonaram a interdição das mulheres nos espaços de poder foram: a revisão na forma de conceber o ministério, que passou a ser um compromisso do casal, e a adoção nos rituais da "pregação de sermões em parcerias". Atrelar a consagração das mulheres à concepção do ministério

\footnotetext{
${ }^{12}$ Maria Goreth SANTOS, 2002; MACHADO, 2003, entre outros.

${ }^{13}$ Entre as históricas se destacam a Igreja Metodista e a Luterana. No pentecostalismo podem ser mencionadas: Universal; Internacional da Graça; Cristo Vive; Renascer; Cristo é Vida; Sara Nossa Terra; Igreja Cristã Ebenézer; Comunidade da Zona Sul; Aliança com Deus; Nacional do Senhor Jesus Cristo; e Cruzada Missionária. As três últimas foram fundadas por mulheres.

14 Ver SANTOS, 2002.

${ }^{15}$ SANTOS, 2002; e MACHADO, 2003

${ }^{16}$ Ver MACHADO, 2003.
} 
do casal foi a fórmula encontrada pelas lideranças de várias denominações para preservar a dependência feminina em relação aos homens. A pregação conjunta também pode ser interpretada como uma forma de enquadrar a participação das mulheres na direção da comunidade religiosa. Assim, se por um lado o crescimento das ordenações femininas sugere uma sensibilidade da liderança masculina com os processos de revisão do lugar social das mulheres na sociedade contemporânea, por outro percebe-se resistências à autonomia feminina e, conseqüentemente, dificuldades em implementar uma política mais eqüitativa de administração da denominação.

Cabe assinalar também o ritmo diferenciado e os distintos caminhos seguidos pelas denominações na ampliação da participação feminina na comunidade e na sociedade inclusiva. A Universal, embora seja a igreja evangélica com maior porcentagem de mulheres em suas fileiras - $62 \%$-, apresenta um grande número de "obreiras" e pouquíssimas pastoras em seus quadros, fato que sugere resistências internas ao processo de revisão das relações desiguais de gênero. Curiosamente, desde os anos 1990, os líderes dessa igreja vêm apoiando candidaturas femininas nas disputas pelo poder legislativo em vários estados e municípios brasileiros. A esta altura, certamente o leitor está se perguntando como interpretar essa situação aparentemente contraditória: estímulo à participação das pentecostais na política eleitoral e resistências internas à ordenação feminina? Ou ainda, quais seriam os impactos dessas estratégias no campo pentecostal como um todo? Para tentar responder a essas questões, recorrerei aos dados de uma recente pesquisa sobre a participação dos evangélicos nos primeiros pleitos eleitorais do século XXI no Estado do Rio de Janeiro.

\section{A política eleltoral: um novo espaço de atuação das pentecostais}

O crescimento demográfico e a força política dos evangélicos no Rio de Janeiro tornaram este estado um verdadeiro laboratório para os interessados nas relações entre a política e a religião no Brasil contemporâneo. Basta lembrar que Rosangela Matheus é a terceira liderança com essa identidade religiosa a assumir o poder executivo nos últimos seis anos ${ }^{17}$ e que os evangélicos representam 37\% dos deputados estaduais eleitos no pleito de 2002. E aqui, uma vez mais, os pentecostais se destacam, revelando uma grande capacidade de transferir a influência da esfera religiosa para a política. Afinal, entre os 26 evangélicos eleitos para Assembléia Legislativa naquele pleito, 18 pertenciam às igrejas pentecostais, verificando-se uma grande concentração na Universal e na Assembléia de Deus: sete e seis parlamentares, respectivamente.

Surpreendentemente, a maioria das parlamentares de identidade evangélica também é pentecostal. Apenas uma entre as cinco deputadas estaduais pertence a um grupo do protestantismo histórico: Maria da Graça Pereira, que é filiada à Igreja Presbiteriana. ${ }^{18}$ Em outro trabalho, analisei a trajetória dessas parlamentares, mas devo lembrar que, assim como no caso do sacerdócio, os projetos de poder da família e os laços conjugais encontram-se entre os fatores que favorecem a participação das pentecostais na esfera política. E mesmo que isso não seja uma especificidade das lideranças evangélicas, é importante registrar a preeminência dos interesses masculinos na definição das linhas de atuação das instituições nos espaços eclesiais e políticos.

\footnotetext{
${ }^{17}$ Anthony Garotinho foi eleito em 1998 e Benedita da Silva o substituiu no comando do Estado em 2002. ${ }^{18}$ As deputadas pentecostais e suas respectivas igrejas são: Andréia Zito (Maranata), Aparecida Panisseti (Batista Renovada), Edna Rodrigues (Universal) e Jurema Batista (Nova Vida) (Maria das Dores Campos MACHADO, Christiane GUIMARÃES, Carla RABELO e Clara OLIVEIRA, no prelo).
} 
Como colocado anteriormente, a base social do pentecostalismo encontra-se nos extratos mais baixos da hierarquia social que dispõem de poucos recursos para a definição do voto e por isso mesmo se mostra mais suscetível à influência da liderança religiosa. Assim, se o político consegue a anuência dos dirigentes da denominação para participar de cultos, distribuir material da campanha e falar com os fiéis, ele não só tem a oportunidade de ter acesso a um grande público, como pode ser reconhecido como um representante dos cristãos. Deve-se lembrar também que tais grupos são constituídos majoritariamente por mulheres e a representação desse segmento no eleitorado brasileiro vem crescendo nas últimas décadas, fator que só aumenta a atração das agremiações partidárias pelas comunidades pentecostais. Assim, desde a implementação da política de cotas no país, em 1996, verifica-se o crescimento gradativo no número de candidaturas femininas evangélicas nos processos proporcionais do Rio de Janeiro e esse crescimento expressa uma estratégia das lideranças partidárias para ampliar seus ganhos eleitorais. Ou seja, na lógica dos dirigentes partidários, as pentecostais que disputam uma vaga no poder legislativo podem com os votos dos irmãos/ãs ajudar a eleger os candidatos do seu partido que atingirem as votações mais expressivas.

Do ponto de vista da liderança religiosa, percebe-se que pelo menos uma das mais importantes igrejas pentecostais já descobriu a importância de apoiar candidaturas femininas: a Universal. A despeito da preferência pelas candidaturas masculinas, os dirigentes dessa denominação há mais de dez anos estimulam mulheres da comunidade a participarem das disputas eleitorais, contando hoje com representantes em várias casas legislativas do Estado do Rio de Janeiro. É importante lembrar que essa denominação dispõe de um Conselho de Bispos que indica os nomes dos candidatos oficiais da Igreja e traça as estratégias das campanhas. A ausência de bispas nessa denominação faz com que as decisões acerca das candidaturas sejam prerrogativas das lideranças masculinas que, dessa forma, controlam a participação feminina nas disputas eleitorais.

De qualquer modo, a indicação das mulheres segue uma lógica pragmática para aumentar $o$ interesse dos partidos pela Universal, uma vez que o lançamento de candidaturas femininas favorece o cumprimento das exigências da legislação eleitoral. Além disso, a predominância feminina na lgreja indica que a identidade de gênero pode favorecer as mulheres na busca de votos no interior da comunidade e alargar as chances de sucesso do grupo nas disputas políticas. A ênfase nas qualidades tradicionalmente alocadas ao gênero feminino por parte das candidatas da Universal resulta desse pragmatismo e, surpreendentemente, não impede a incorporação de temas do imaginário feminista nas suas respectivas agendas políticas. Afinal, desde o primeiro pleito do século XXI, percebe-se a inclusão de temáticas como cidadania feminina, luta de gêneros, direitos das mulheres, etc. nos discursos das políticas dessa igreja. ${ }^{19}$

Por outro lado, as campanhas e os seminários de formação de lideranças políticas realizados pelos conselhos de defesa das mulheres, partidos políticos e ONGs feministas têm ajudado na difusão da questão de gênero e da luta pela presença maior das mulheres nas instâncias de representação política entre as pentecostais relutantes em estreitar os laços com o feminismo. ${ }^{20}$ A participação nesses espaços pode resultar na ampliação da capacidade crítica e na criação de zonas de autonomia das lideranças políticas em relação à instituição religiosa, mas isso só o tempo poderá mostrar.

Uma outra novidade no campo pentecostal foi o aparecimento de uma militância política feminina que gratuitamente trabalha pelos candidatos da Igreja Universal. São

${ }^{19}$ MACHADO e FIGUEIREDO, 2002; e MACHADO, GUIMARÃES, RABELO e OLIVEIRA, no prelo.

${ }^{20}$ MACHADO, GUIMARÃES, RABELO, OLIVEIRA, no prelo. 
mulheres que, independentemente da idade, passam a atuar junto com os homens da igreja, empunhando bandeiras e distribuindo santinhos pelas ruas, como os já tradicionais cabos eleitorais. A diferença encontra-se na motivação religiosa e no caráter voluntário dessa militância. Segundo a parlamentar Edna Rodrigues, esse voluntariado representa um "ouro nas mãos dos políticos" ou uma vantagem a mais dos candidatos da igreja que dispõem de uma militância aguerrida sem pagar nem mesmo a boca de urna.

Essa forma de participação política das mulheres nos processos eleitorais merece uma análise mais aprofundada, uma vez que um estudo recente, realizado pela Fundação Perseu Abramo, indica que a influência e a importância da política no dia-a-dia das mulheres brasileiras variam em função do grau de escolaridade, da renda familiar e do engajamento no mercado formal de trabalho. Dito de outra maneira, são as mulheres que apresentam os maiores níveis de escolaridade e de renda, e que integram de alguma forma a população economicamente ativa, as que mais valorizam a política. Já as mulheres pobres, pouco instruídas e excluídas do mercado de trabalho tendem a achar a política "mais ou menos importante ou nada importante" para o seu cotidiano. ${ }^{21}$ Uma vez que as pentecostais se enquadram justamente neste último segmento, torna-se plausível a hipótese de que as militantes da Universal estejam encontrando outros elementos na comunidade religiosa que compensem os baixos níveis de renda e instrução e a ausência de atividades remuneradas que constituem variáveis importantes na valorização da política.

Sabe-se que a política eleitoral é um tema tratado no púlpito da Igreja e que isso possibilita a socialização das opiniões e a influência das lideranças religiosas sobre os fiéis que, além dos níveis elementares de educação, apresentam pouca ou nenhuma participação em movimentos sociais, organizações associativistas ou político-partidária. Assim, a comunidade se transforma em uma base eleitoral importante, e seus membros em ativistas potenciais que, quando conclamados pela liderança, invadem as ruas com o propósito de eleger um político/a cristão/ã. Sinteticamente, poder-se-ia afirmar que a rede de relações religiosas desdobra-se em uma poderosa rede de relações políticas e que as fervorosas fiéis aprendem a importância do ativismo político-religioso.

\section{Considerações finais}

Neste artigo foram assinaladas as principais transformações em curso nas representações e relações de gênero entre os pentecostais. Discutiu-se a reconfiguração da subjetividade masculina e demonstrou-se que uma das conseqüências não intencionais da adesão das mulheres ao pentecostalismo é justamente a ampliação da autonomia dessas fiéis em relação aos seus parceiros e familiares. Argumentou-se ainda que os constrangimentos sociais que enquadram a participação da mulher pentecostal na esfera pública foram em parte alterados e em parte acomodados às antigas prescrições de gênero. No caso do sacerdócio, verificou-se que, a despeito do crescimento do número de sacerdotisas, a associação da ordenação feminina com o ministério do casal expressa uma continuidade com o ideário cristão. No que se refere à participação dos pentecostais na política eleitoral, registrou-se o aumento do número de mulheres nos distintos níveis do poder legislativo do Estado do Rio de Janeiro, mantendo-se, porém, a preferência das lideranças religiosas pelas candidaturas masculinas e o controle dos homens na atuação política feminina.

Nesse contexto de ambivalências, a Universal se destacou pelo fato de ser a igreja mais feminina, estimular a entrada das mulheres no mercado de trabalho, fomentar o

${ }^{21}$ Ver Tatau GODINHO, 2004, p. 150. 
ativismo político e apoiar candidaturas das fiéis nas disputas eleitorais, ao mesmo tempo que mantém um controle sistemático sobre o processo de ascensão das mulheres na hierarquia religiosa e na formação de lideranças políticas femininas. O sucesso dessa denominação na ampliação de sua capacidade de influência na sociedade brasileira a colocou na frente do processo de flexibilização e revisão do pentecostalismo, com suas estratégias sendo pouco a pouco assimiladas pelas demais estruturas eclesiásticas. E aqui é preciso prudência: o efeito mimético expressa mais o acirramento da competição religiosa e a preocupação dos dirigentes das outras igrejas com o fortalecimento da Universal do que uma unidade interna no campo pentecostal. De qualquer maneira, o embate entre os grupos religiosos até agora parece ter sido positivo para a criação de novas formas de enquadramento da participação de homens e mulheres dos segmentos populares nos espaços eclesiais, econômicos e políticos.

\section{Referências bibliográficas}

GODINHO, Tatau. "Democracia e política no cotidiano das mulheres brasileiras". In: VENTURI, Gustavo; RECAMAN, Marisol; OLIVEIRA, Suely (Orgs.). A mulher brasileira nos espaços público e privado. São Paulo: Fundação Perseu Abramo, 2004. p. 149-159.

GOUVEIA, Eliane Hojai. Imagens femininas: a reengenharia do feminino pentecostal na televisão. 1998. Tese (Doutorado em Sociologia da Religião) - Programa de PósGraduação em Ciências da Religião da PUC, São Paulo.

JACOB, César Romero et al. Atlas da filiação religiosa e indicadores sociais no Brasil. Rio de Janeiro: Ed. PUC-Rio; São Paulo: Loyola, 2003.

MACHADO, Maria das Dores Campos. Os efeitos da adesão religiosa na esfera familiar. São Paulo: ANPOCS, 1996.

"SOS Mulher: a identidade feminina na mídia pentecostal". Ciências Sociales y Religión, Porto Alegre, v. 1, p. 167-188, 1999.

"Neopentecostalismo: continuidades e descontinuidades nas representações e relações de poder entre os gêneros". Caminhos, Goiânia: Editora da UCG, v. 2, n. 2, p. 67-81, 2003

MACHADO, Maria das Dores Campos; FIGUEIREDO, Fabiana. "Religião, gênero e política: as evangélicas nas disputas eleitorais da cidade do Rio de Janeiro". Ciências Sociais e Religião, Porto Alegre: Ed.UFRGS, v. 4, p. 125-148. 2002.

MACHADO, Maria das Dores Campos; GUIMARÃES, Christiane; RABELO, Carla; OLIVEIRA, Clara. "A políitica: um novo espaço de articulação das identidades religiosas e de gênero". Mandrágora, São Bernardo dos Campos: Editora da Universidade Metodista, n. 10, no prelo.

MACHADO, Maria das Dores Campos; MARIZ, Cecília Loreto. "Sincretismo e trânsito religioso". A Dança do Sincretismo - Comunicações do ISER, ano 13, n. 45, p. 24-34, 1994.

"Pentecostalismo e a redefinição do feminino". Religião e Sociedade, Rio de Janeiro: ISER, v. 17, n. 1, p. 140-159, 1996.

. "Mudanças recentes no campo religioso brasileiro". Antropolítica, Niterói: EDUFF, v. 5 , p. 21-44, 1999.

. "Mujeres em três grupos religiosos em Brasil: uma comparación entre pentecostales y católicas". In: MARCOS, Silvia (ed.). Religión y gênero. Madrid: Editorial Trotta. 2004. p. 203.231.

PIERUCCI, Antônio Flávio. "Bye Bye, Brasil: o declínio das religiões tradicionais no Censo de 2000". Estudos Avançados, São Paulo: Ed. da USP, n. 52, p. 17-28, 2004. 
SANTOS, Maria Goreth. A mulher na hierarquia evangélica: o pastorado feminino. 2002. Dissertação (Mestrado em Sociologia) - Programa de Pós-Graduação em Ciências Sociais da UERJ, Rio de Janeiro.

SOARES, Vera. "O feminismo e o machismo na percepção das mulheres brasileiras". In: VENTURI; Gustavo; RECAMÁN, Marisol; DE OLIVEIRA, Suely (Orgs.). A mulher brasileira nos espaços público e privado. São Paulo: Editora Fundação Perseu Abramo, 2004. p. 161-182.

TARDUCCI, Monica. "O Senhor nos libertou". Cadernos Pagu, Campinas: Núcleo de Estudos de Gênero, v. 3, p. 143-163, 1994.

WEISS, Rosa Amélia de Almeida. Trânsito religioso no Brasil: a múltipla pertença de mulheres católicas em São José dos Campos. 2002. Dissertação (Mestrado em Ciências da Religião) - Programa de Pós-Graduação em Ciências da Religião, PUC, São Paulo.

\section{Representations and Gender Relations in Pentecostal Groups}

Abstract: The objective of this article is to conduct an evaluation of the main changes produced throughout the last fifteen years in the hegemonic gender system of pentecostalism. After presenting the demographic and socio-economic profile of Pentecostals, I discuss the consequences of religious choice for men and women, and the limits of the rearrangement process of female and male subjectivities inside the communities. The growth trends of female priesthood and the political participation of pentecostal women are also analysed, to help us understand the ambivalences in reviewing the representations and gender relations in these religious groups.

Key Words: gender relation, pentecostalism, politics. 